\title{
COVID-19 - A TALE OF TWO CITIES: SEATTLE AND VANCOUVER
}

\author{
Ben Y. F. FONG', Vincent T. S. LAW' \\ 1. School of Professional Education and Executive Development, College of Professional and Continuing Education, The Hong \\ Kong Polytechnic University, Hong Kong, China
}

Correspondence: ben.fong@cpce-polyu.edu.hk

\begin{abstract}
The coronavirus pandemic has been affecting many countries in the world over the past six months. Nowhere sees the light at the end of the tunnel. Precautionary measures, lockdown, as well as control of crowd gathering and movement have been implemented by all governments, with the sacrifice of economic activities. It is interesting to review how things were happening in North America where the United States has been hard hit by the coronavirus disease 2019 (COVID-19), scoring over two million confirmed cases and about 120 thousand deaths at the top of the list of the world. Canada ranked eighteenth with about 100 thousand cases and just about 8 thousand deaths. Both the cases and deaths per capita are lower in Canada, which shares the same border and similar culture with the United States. Seattle and Vancouver have some of the highest incomes and educational levels in both countries. These two West coast cities are only 200 kilometres apart and are near the U.S.-Canada border. They are selected for this review to study the different approaches in managing the COVID-19 pandemic.
\end{abstract}

\section{KEYWORDS}

coronavirus; pandemic; COVID-19; health care systems; public health; social distancing; masks

\section{INTRODUCTION}

Esteemed microbiologists Sir Frank Macfarlane Burnet and David White said in 1972 that 'the most likely forecast about the future of infectious diseases is that it will be very dull' and 'there was always a risk of some wholly unexpected emergence of a new and dangerous infectious disease.' From Legionnaires' disease first discovered in the 1970s, to AIDS, Ebola, the severe acute respiratory syndrome (SARS), and now the coronavirus disease 2019 (COVID-19), infectious diseases continue to affect the world populations. As of 18 June 2020, there have been 8,061,550 confirmed cases of COVID-19, including 440,290 deaths, resulting in a world mortality rate of 5.46\%. [1] Experts have warned that half of the population in the world will be affected by the end of 2020 , potentially leading to more than 100 million deaths. [2]

As of 18 June 2020 , about $37.3 \%$ of the world's COVID-19 cases (i.e. 3.9 million cases) occurring in the North America. [3] In the 331 million population of the United States of America (U.S.), there were nearly 2.4 million confirmed cases or a prevalence of $0.72 \%$, and nearly 116 thousand deaths or a mortality rate of nearly $4 \%$ among the confirmed cases. In Canada, there were 99.1 thousand cases or a prevalence of $0.26 \%$, and 8,175 deaths or a mortality rate of $8.25 \%$. [4] The confirmed COVID-19 cases and deaths in the U.S. were 29.3 times and 14.2 times respectively those of Canada. Seattle and Vancouver are selected for this review to study the different approaches in managing the COVID-19 pandemic. Seattle, with a population of 3.5 million in the metropolitan area, and city of Vancouver, with a population of about 631.5 thousand, are two border cities at the West coast that are only 200 kilometres apart. Comparison is also made with reference to Hong Kong (H.K.) as Seattle and Vancouver have 14\% and $20 \%$ of Asian population respectively. Both cities are 
amongst the highest incomes and educational levels in both countries.

\section{HEALTH CARE SYSTEMS OF UNITED STATES AND CANADA}

The U.S. and Canada are culturally similar, but their health care systems are very different. The U.S. system is heavily private with multiple payers whereas Canada has a predominantly publicly-funded single-payer approach, providing universal access and being more equitable. [5] The U.S. has $16 \%$ of its GDP spent on health care, much more than the $10.4 \%$ in Canada, whose system works better than the U.S. on health outcomes such as life expectancy, 83 versus 79 years, and mortality rate. However, the Americans are more satisfied with the health services provided and consider the quality of care as excellent. [6]

Public health is defined as 'the art and science of preventing disease, prolonging life and promoting health through the organized efforts of society'. [7] There are activities to enhance public health capacities and services with the aim to improve health and wellbeing of the people. This function is obvious and crucial during disasters and pandemics. In the U.S., State and Local Health Departments are primarily responsible for health under the U.S. Constitution while the Federal Government will ensure the capability of all levels of government to provide essential public health services and to act when health threats affect more than one state, a region, or the whole country. [8] However, health care in the U.S. is provided mainly by private for-profit corporations, attending to the needs of individuals rather than those of the public. Thus, a real public health system does not exist in the U.S., and there appears to be no capacity to protect the population.

In Canada, the Minister of Health has the responsibility to maintain and improve the health of Canadians, with supports by Health Canada, the Public Health Agency of Canada, the Canadian Institutes of Health Research, and the Patented Medicine Prices Review Board. The Public Health Agency of Canada (PHAC) is remarkably like the Centres for Disease Control and Prevention (CDC) in the U.S. It aims to empower Canadians to improve personal health, through activities with partnership organisations by the public health mandate contained in legislation and regulations within each province and territory. The provincial bureaucracy carries out all core functions, roles, and responsibilities. $[9,10]$
In British Columbia (BC), the first case appeared on 28 January 2020 and community transmission in Canada was first confirmed in BC on 5 March 2020. Two weeks later, a public health emergency was declared in the province when Vancouver was also in a local state of emergency. [11] As of 11 June 2020, there were 2,709 cases in BC with 168 deaths and half of the cases, i.e. 1,396 cases and 74 deaths, occurred in Vancouver. The figures in BC were $3 \%$ and $2 \%$ of those in the country respectively, but the population of BC is $13.5 \%$ of Canada. The province has done well in combating the epidemic through effective precautionary measures such as crowds of over 50 people being banned. Restaurants, nightclubs, bars, as well as all personal service establishments were ordered to close in late March. Physical distancing was imposed in public venues. Many cities, including Vancouver, had closed public playgrounds.

The BC government has produced COVID-19 curveflattening results that are the envy of the rest of Canada. It has been cautious about renewing physical connections and modifying public measures during the gradual reopening of the province to contain the infection rate. Part of the "success" is attributed to random factors specific to $B C$, including a large Chinese community that practised physical social distancing very early in the epidemic, warmer weather, and the timing of the spring break. BC is a model for Canada in getting things under control quickly, particularly in limiting social contacts. [12] However, the elderly and people with pre-existing medical conditions are more vulnerable to the virus. Most of the COVID-19 fatalities in Canada involve residents of care homes. This suggests a systemic failure on how the most vulnerable members of society are being cared for. [13]

Seattle is a seaport city on the West Coast of the U.S. and was the fastest-growing major city in 2013. The population of Seattle metropolitan area is 3.98 million and is the largest city in the state of Washington. In March 2020, Seattle was better prepared, learning from the 3-day strike by caregivers at Swedish Health Services, the largest non-profit health care provider in Seattle, and putting systems in place to safely serve the patients. Physicians continued to work and displayed highly reliable work behaviours. The management synthesised the improvements in organisational practices, particularly in clear communication with repetition, and delegation of 
authority. Seattle is the city of the first diagnosed COVID-19 cases and mortalities in the U.S. [14] The "unplanned" strike happened to be a life-saving exercise when COVID-19 struck Seattle. They had found measures with focus on people and sustainability would result in effective crisis management for the city. Such measures, together with the quick actions by the leaders of the Washington state and Seattle, helped to boost the ability of Seattle to serve its people in this time of radical uncertainty. [15] COVID-19 tests performed in the communities have improved alertness in the population.

\section{COPING APPROACHES OF UNITED STATES AND CANADA}

Professor Peter Berman, a health economist who has taught on both sides of the U.S.-Canada border, has examined the difference between the U.S. and Canada. In early May, he noted over 62,000 cases and 3,562 deaths reported in Massachusetts, or 52 fatalities for every 100,000 people; while in $\mathrm{BC}$, there were just 2,112 cases and 111 deaths, or about two victims for every 100,000 population. In the U.S., hospitals are mostly private organisations without any overall government control whereas in BC, the provincial minister of health, with the advice of the provincial health officer, can instruct health authorities and facilities to take whatever actions are required. Moreover, while the American system has much expertise, there is little national coordination and divided responsibility, plus at times conflicts, even among agencies such as the National Institutes of Health, the Centre for Disease Control, and the coronavirus task force set up by the President. In Canada, community doctors are private providers and thus primary care and the hospital systems are not connected, making it difficult to enforce testing for the COVID-19 out into the population. [16]

In March when cases started to surge in the U.S., its President played down the threats of the coronavirus pandemic because the national economy needed to resume normally, despite warning from experts that the worst of the COVID-19 pandemic had yet to be experienced in the country. On the other side of the Atlantic, the British Prime Minister closed all nonessential shops, restricted travel, and enforced social distancing, by the police if necessary. The governors in the U.S. were doing a better job in handling the coronavirus outbreak, by bringing in stay-at-home orders, as well as closing nonessential businesses and schools. The U.S. has been leading the world in the number of cases and deaths since late March 2020. Americans are not vigilant enough in conforming to rules and advice from the authorities. $[17,18]$

Nonetheless, Seattle and San Francisco have managed better than many other U.S. cities during the pandemic. In addition to effective government policies, Challenge Seattle, an organisation made up of representatives from giant Seattle companies, including Amazon, Microsoft, Starbucks, Boeing, and Nordstrom, have been playing a major role in getting the business community to take the outbreak seriously, and they sent employees to work from home, thus mitigating the spread. With such involvement of the private sector, Seattle was able to address the pandemic earlier than other cities, especially when the vast supply networks of epidemic prevention supplies and international connections can play the important role in, for example, the procurement of 250,000 N95 masks for the Washington state. [19]

\section{WHAT HAS BEEN AND CAN BE LEARNED ACROSS THE US-CANADA BORDER AND THE CONTINENTS?}

It was truly shocking that the situation in the U.S. was getting worse because of the power and influence of its President, who has been making "contradictory" statements publicly and in his personal blog. It was almost two months after the surge of cases in the U.S. that the President had finally overcome his aversion to wearing masks in May during a visit to a vehicle factory. Ironically, the President, who was pushing to get his people to put the pandemic behind them and reopen the faltering economy, had never worn a mask in the public. [20]

In May, the Canadian Prime Minister started to wear a face mask in the public, especially when social distancing was not possible. He and his family had self-isolated at home for several weeks after his wife was diagnosed with COVID-19 in March. Canadian officials also emphasised the importance of other guidance to limit the spread of the COVID-19, including frequent handwashing and keeping two metres (six feet six inches) from others. The Chief Public Health Officer said face masks were recommended as an additional protection when physical distancing was hard to maintain, and that staying home when sick was a must because of more evidence about asymptomatic and presymptomatic individuals spreading the virus. [21] 
Together with other western countries, the United Kingdom (U.K.) was caught unprepared because of no experience or expertise in dealing with such fast changing "natural" disaster. The U.K. and U.S. may be suffering from the arrogance or ignorance especially among the leaders, and because of a lack of action for weeks. The basic principles and practice of public health and infectious control were ignored for unknown reasons. Then the U.K. government had a new plan: Suppress-Shield-TreatPalliate. The plan had arrived far too late in the development of the outbreak and the National Health Service (NHS) was not prepared for the surge of extremely sick patients that followed. There was also a lack of personal protective equipment and sound clinical leadership, resulting in panic and chaos within the NHS. [22]

In Europe, Germany is coming through this crisis relatively well, with 187 thousand cases and half of the case per capita of that of U.K. This is attributed to the German health care system in which all people have full access to medical care, supported by a network of general practitioners ready to deal with milder cases, allowing the hospitals to focus on the more severely ill. The government also took the COVID-19 threat seriously from the beginning. It informed the public not just about what they knew, but also about what they did not know. There were no national curfews, but citizens were asked to stay at home voluntarily and to live under severe restrictions in public and private life. Everyone remained vigilant, demonstrating a sense of responsibility for themselves and others. Transparent and accurate information was shown to be more effective than coercion. Germany also pointed out the need for globallevel crisis management with multilateral cooperation. No single country could manage a pandemic alone. [23]

In the small town of Lodi, Lombardy of Italy, a major economic region with a population of 10 million in the northern Italian region, the infection exploded and became the epicentre of the European outbreak. The health system had made the biggest mistake by admitting COVID-19 patients into hospitals throughout the region. It should have established separate exclusive facilities for patients with coronavirus, like the alternative care sites in the U.S. and U.K. [24] In addition, a much centralised health care system with big hospitals as its core was attributing to the acceleration of the outbreak in northern Italy by acting as conductors of infection. It had learned that local community health services, including health clinics, family doctors, community nursing and rehabilitation facilities, were essential in combating outbreaks of this scale. Thus, the existence of advanced hospitals in Italy, with the not so advanced community health facilities, help to explain the spread of COVID-19. [25]

Dealing with health-related matters is never simple or straightforward since the outcome cannot be predicted even with the most powerful tool like big data analysis and super-computers. Health care is neither a commodity, as in the case of U.S., or wholly welfare, as in U.K. and Canada. The dual track system in Hong Kong, with both public and private sectors working in parallel to suit the needs of individuals while providing a universal healthcare safety net, is among the best in the world. [26] The Singaporeans are smart in modifying the H.K. system to perform better in imposing more co-payment incentives, which are obligations and self-responsibility in one's health. Across the border, Mainland China's health services used to be very privately oriented, but in a socialist economy, have been moving towards more state funding, particularly in primary care, supplemented by health insurance.

Nonetheless health care systems often reflect the political and social philosophy of the nation. With COVID-19 or any disastrous events, the health care systems are being tested to beyond capacity. Hence the disastrous scenes and untoward happenings have been shown in European countries and the U.S. In U.S.-Canada, concern about the undefended border is real because the novel virus has neither nationality nor preference for any nations. It has just spread through careless human habits and unguarded communities. Different systems should manage differently with different considerations, but in time of a pandemic all nations must act fast in cohesion and collaboration, not through coercion and never in opposition.

In Hong Kong, the government was quick to introduce the 'preparedness and response plan for the novel infectious disease of public health significance' and hence was sufficiently prepared for the coronavirus pandemic. The government also reminded residents to pay attention to personal and environmental hygiene via social media. Such community-oriented actions were found to work in containing the outbreak. In addition, the Centre for Health Protection and the Hospital Authority held daily press conferences and a designated official website was providing updates on the outbreak, health guidelines and pertinent information to the public, etc. There is no doubt that wearing face masks, partial lockdown, social distancing, tests, border control and quarantine centres 
have been shown to work for the success of Hong Kong in combating COVID-19. [27]

\section{References}

1. World Health Organization. WHO Coronavirus Disease (COVID-19) Dashboard [Internet]. 2020 [updated 2020; cited Jun 17, 2020]. Available from:

https://covid19.who.int/?gclid=CjwKCAjw_qb3BR AVEiwAvwq6Vtz8Ye0g5xWCOYFNMCQENQJ_EVH 3ilNqNqWFU-

itWEMPT8M8rpVnwRoCLsQQAvD_BwE

2. Jones, D. S. History in a crisis-lessons for Covid-19. New England Journal of Medicine. 2020;382(18):1681-1683.

3. COVID-19 Visualizer. Home page [Internet]. 2020 [updated 2020; cited Jun 17, 2020]. Available from: https://www.covidvisualizer.com/

4. World Health Organisation. Explore the Data [Internet]. 2020 [updated 2020; cited Jun 17, 2020] Available from: https://covid19.who.int/explorer

5. The National Bureau of Economic Research. Comparing the U.S. and Canadian Health Care Systems [Internet]. 2020 [updated 2020; cited Jun 17, 2020]. Available from: https://www.nber.org/aginghealth/fall07/w13429. $\mathrm{html}$

6. The Peter G. Peterson Foundation How does the U.S. healthcare system compare to other countries? 2019 [updated 2019; cited Jun 17, 2020] Available from: https://www.pgpf.org/blog/2019/07/how-doesthe-us-healthcare-system-compare-to-othercountries

7. World Health Organization. Public health services [Internet]. 2020 [updated 2020; cited Jun 17, 2020]. Available from: https://www.euro.who.int/en/healthtopics/Health-systems/public-health-services

8. Institute of Medicine (US) Committee for the Study of the Future of Public Health. The Future of Public Health. Washington (DC): National Academies Press (US); 1988. Available from: https://www.ncbi.nlm.nih.gov/books/NBK218212/
9. The Government of Canada. Health Portfolio [Internet]. 2017 [updated 2017; cited Jun 17 2020]. Available from:

https://www.canada.ca/en/healthcanada/corporate/health-portfolio.html

10. Canadian Public Health Association. Public Health in the Context of Health System Renewal in Canada [Internet]. 2019 [updated 2019; cited Jun 17, 2020]. Available from:

https://www.cpha.ca/public-health-contexthealth-system-renewal-canada

11. Little, S. Coronavirus: B.C. declares public health emergency amid 3 new deaths and 83 new cases. Global News [Internet]. 2020 Mar 18 [cited 2020 Jun 17]. Available from:

https://globalnews.ca/news/6691983/bccoronavirus-update-tuesday-march-17/

12. Young, I, British Columbia is winning the coronavirus fight. Did it get lucky with weather, holidays and a shrewd Chinese community? South China Morning Post [Internet]. 2020 Apr 8 [cited 2020 Jun 17]. Available from: https://www.scmp.com/news/world/unitedstates-canada/article/3078875/coronavirus-britishcolumbia-winning-covid-19-fight

13. City of Vancouver. COVID-19 (Coronavirus) [Internet]. 2020 [updated 2020; cited Jun 17 2020]. Available from: https://vancouver.ca/homeproperty-development/covid-19-coronaviruswithin-vancouver.aspx

14. Miller, G., Buck, C., Kang, C., Aviles, J., Younggren, B., Osborn, S, Keay, C. COVID-19 in Seattle - Early Lessons Learned. Journal of the American College of Emergency Physicians Open. 2020; 1:85-91.

15. Dale, C., Welling, L. \& Clearfield, C. How One Seattle Health System Is Managing the COVID-19 Crisis. Harvard Business Review [Internet]. 2020 Apr 21 [cited 2020 Jun 17]. Available from: https://hbr.org/2020/04/how-one-seattle-healthsystem-is-managing-the-covid-19-crisis

16. Austen, I. Two Medical Systems, Two Pandemic Responses. The New York Times [Internet]. 2020 May 1 [cited 2020Jun 17]. Available from: https://www.nytimes.com/2020/05/01/world/can ada/america-canada-coronaviruscomparison.html

17. Taylor, A., Hawkins, D., Kornfield, M., Sonmez, F., Dougherty, J. Armus, T. Trump endorses ending 
coronavirus social distancing soon, against health experts' advice. The Washington Post [Internet]. 2020 March 24 [cited 2020 Jun 17]. Available from: https://www.washingtonpost.com/world/2020/03/ 23/coronavirus-latest-news/

18. Worldometer. Coronavirus [Internet]. 2020 [updated 2020; cited Jun 17 2020]. Available from: https://www.worldometers.info/coronavirus/

19. Vanian, J. What Seattle and San Francisco can teach us about mitigating the scourge of COVID19. Fortune [Internet]. 2020 April 23 [cited 2020 Jun 17]. Available from: https://fortune.com/2020/04/22/seattle-sanfrancisco-covid-coronavirus/

20. France-Presse, A. Coronavirus: Donald Trump says he finally wore a mask and 'it looked very nice'. South China Morning Post [Internet]. 2020 May 22 [cited 2020 Jun 17]. Available from: https://www.scmp.com/news/world/unitedstates-canada/article/3085546/coronavirusdonald-trump-says-he-finally-wore-mask

21. France-Presse, Agence. Coronavirus: Justin Trudeau dons face mask as Canada urges public to do the same. South China Morning Post. [Internet]. 2020 May 21 [cited 2020 Jun 17]. Available from: https://www.scmp.com/news/world/unitedstates-canada/article/3085356/coronaviruscanada-recommends-masks-first-time

22. Horton, R. Offline: COVID-19 and the NHS - "a national scandal". The Lancet. 2020;395(10229):1022.

23. Spahn, J. How Germany contained the coronavirus. The World Economic Forum COVID Action Platform [Internet]. 2020 May 23 [cited 2020 Jun 17]. Available from: https://www.weforum.org/agenda/2020/05/howgermany-contained-thecoronavirus? fbclid=IwAR I qimjXaYIMoQaj6RAahIK OAoCn2-Tn9kzfUFLagekK53utsMCr_mEgz4c

24. MeyerGregg, S., BlanchfieldBonnie, B., BohmerRichard, M. J., \& Craig, V. Alternative Care Sites for the Covid-19 Pandemic: The Early US and UK Experience. NEJM Catalyst Innovations in Care Delivery. 2020.

25. Williams, M. The lessons Italy has learned about its COVID-19 outbreak could help the rest of the world. CBC News [Internet]. 2020 April 2 [cited
2020 Jun 17]. Available from:

https://www.cbc.ca/news/covid-19/italy-covid19-outbreak-lessons- 1.5517520

26. Ng, T., Fong, B., Kwong, C. Transition of hospital acute-centric to long term care in an ageing population in Hong Kong - Is it an issue of service gap?. Asia Pacific Journal of Health Management. 2019;14(1):11-15.

27. Wong S. Y.S., Kwok, K. O. Chan, F. K.L. What can countries learn from Hong Kong's response to the COVID-19 pandemic? CMAJ. 2020;192(19 E): E511-E515. 